\title{
Nomogram Prediction of Severe Risk in Patients With COVID-19 Pneumonia: A Retrospective Study
}

Fang Zheng

The first hospital of Changsha

\section{Run Yao}

Xiangya Hospital Central South University

Jiyang Liu

First Hospital of Changsha

\section{Ruochan Chen}

Xiangya Hospital Central South University

Ning Li ( $\square$ liningxy@csu.edu.cn )

Xiangya Hospital Central South University

\section{Research article}

Keywords: SARS-CoV, COVID-19, prediction, nomogram

Posted Date: July 24th, 2020

DOI: https://doi.org/10.21203/rs.3.rs-42479/v1

License: (c) (1) This work is licensed under a Creative Commons Attribution 4.0 International License. Read Full License 


\section{Abstract \\ Background}

COVID-19 elicits a range of different responses in patients and can manifest into mild to very severe cases in different individuals, depending on many factors. We aimed to establish a prediction model of severe risk in COVID-19 patients, to help clinicians achieve early prevention, intervention, and aid them in choosing effective therapeutic strategy.

\section{Methods}

We selected confirmed COVID-19 patients who admitted to First Hospital of Changsha city between January 29 and February 15, 2020 and collected their clinical data. Multivariate logical regression was used to identify the risk factors associated with severe risk. These factors were incorporated into the nomogram to establish the model. The ROC curve, calibration plot and decision curve were used to assess the performance of model.

\section{Results}

239 patients were enrolled and 45 (18.83\%) patients developed severe pneumonia. Univariate and multivariate analysis showed that age, COPD, shortness of breath, fatigue, creatine kinase, D-dimer, lymphocytes and h CRP were independent risk factors for severe risk in COVID-19 patients. Incorporating these factors, the nomogram achieved good concordance indexes of 0.873 (95\% Cl: $0.819-0.927)$, and well-fitted calibration plot curves. The model provided superior net benefit when clinical decision thresholds were between $10-70 \%$ predicted risk.

\section{Conclusions}

Using the model, clinicians can intervene early, improve therapeutic effects and reduce the severity of COVID-19, thus ensuring more targeted and efficient use of medical resources.

\section{Introduction}

First reported in Wuhan in December 2019, coronavirus disease 2019 (COVID-19), caused by the severe acute respiratory syndrome coronavirus 2 (SARS-CoV-2), has rapidly spread throughout China and all over the world (1-3). Viral genome sequencing revealed SARS-CoV- 2 to be a member of the $\beta$-coronavirus family, which also includes the Middle East syndrome coronavirus (MERS-CoV) and severe acute respiratory syndrome coronavirus (SARS-CoV) $(4,5)$. As a result of its rapid global spread and high infectiousness, the World Health Organization (WHO) declared the COVID-19 outbreak a "Public Health Emergency of International Concern" (PEHIC) on 30 January 2020. According to the official report 
released by the WHO, as of July 7, 2020, a total of 11,919,501 laboratory-confirmed cases have been found worldwide, with 545,269 fatalities.

COVID-19 has the characteristics of strong infectivity and complex clinical manifestations. Despite most COVID-19 patients presenting with mild symptoms, acute lung injury, respiratory distress syndrome, multiple organ dysfunction and even death can occur in severe cases (2-6). Initial clinical and epidemiological data have shown that around $26-33 \%$ of patients need intensive care, and the mortality rate was $4-15 \%(4,7,8)$. A large-scale case study including 72,314 patients infected with COVID-19 revised the initial estimates from China, and it reported that $14 \%$ developed into severe cases, with a fatality rate of $2.3 \%$ (9). Considering the huge population of COVID-19 cases globally, the number of severe cases has been enormous as well. Therefore, exploring risk factors to predict the severe cases is crucial for early intervention and treatment. Currently, there are few reports on the evaluation of COVID-19 related risk factors at home and abroad $(6,10-13)$. Our study retrospectively analyzed the clinical data of 239 patients admitted to the first hospital of Changsha City and constructed a novel model to assess severe risks for patients with COVID-19. It aimed to offer a better understanding on the disease progression occurring after SARS-CoV-2 infection, and establish a basis for optimizing the current therapeutic strategies.

\section{Methods}

\section{Patients}

All 239 confirmed patients with COVID-19 admitted to First Hospital of Changsha from January 29 to February 15, 2020 were included in our study. The First Hospital of Changsha was designated as "the specific hospital for the treatment of severe patients with COVID-19 in Changsha" by the government during the epidemic.

\section{Definitions}

Diagnosis was confirmed by detecting SARS-CoV-2 RNA in nasopharyngeal swab samples using a virus nucleic acid detection kit according to the manufacturer's protocol (Shanghai Bio Germ Medical Biotechnology Co., Ltd). Patients were classified into non-severe and severe type based on the severity of symptoms (11). The severe-type was defined according to the following criterion: 1 . Respiratory distress with the respiratory rate over 30 per minute; 2 . Pulse oximeter oxygen saturation $\leq 93 \%$ in the resting state while breathing ambient air; 3 . Arterial blood oxygen partial pressure ( $\mathrm{PaO} 2)$ / oxygen concentration $(\mathrm{FiO} 2) \leq 300 \mathrm{mmHg}(1 \mathrm{mmHg}=0.133 \mathrm{kPa})$.

\section{Data collection}

We retrospectively collected the information of all patients including demographic data, clinical characteristics, and laboratory parameters. The demographic data included age, gender and epidemiology. The clinical characteristics included time between onset and hospitalization, underlying diseases (hypertension, diabetes, coronary heart disease, COPD, kidney disease, cerebral infarction and 
liver disease) and symptom (fever, cough, shortness of breath, muscle ache, headache, dizziness, diarrhea, fatigue, nausea and sore throat). The laboratory parameters included creatine kinase isoenzyme, creatine kinase, lactate dehydrogenase, triglyceride, total cholesterol, high density lipoprotein, low density lipoprotein, D-dimer, leucocytes, hemoglobin, platelet count, lymphocytes, neutrophils, eosinophils, high-sensitivity C-reactive protein (h CRP), alanine aminotransferase, aspartate aminotransferase, total bilirubin, albumin, albumin / globulin, creatinine and urea nitrogen. Two medical staffs independently reviewed the data to ensure the accuracy of the collected data.

\section{Statistical analyses}

Continuous variables were described as means \pm SD or median (interquartile range (IQR)) and categorical data were presented as number and percentage. The difference between the non-severe group and severe group was compared using Mann-Whitney test or $t$-test for continuous data and Chi-squared tests for categorical variables.

Univariate and multivariate logistic regression were performed to explore the association of clinical characteristics and laboratory parameters with the severe risk in patients with COVID-19. A backward step-down process was used to select variables in the final model for the nomogram. The receiver operating characteristic (ROC) curve was used to evaluate the discriminatory ability of the model. The calibration plot measured the relationship between the model's predicted probability and the actual probability. The Hosmer-Lemeshow test was used to assess model calibration. To evaluate the clinical value of the prediction model, we plotted a decision curve to inform clinicians about the range of threshold probabilities. By determining the relationship between a chosen predicted probability threshold and the relative value of false-positive and false-negative results, decision curve analysis shown the net benefit value of using the model at that threshold. Then we gain insights into the clinical consequences of using the prediction model (14).

The statistical analyses were 2-tailed and $P$ value $<0.05$ was considered statistically significant. All the statistical analyses were performed with R (http://www.R-project.org) and EmpowerStats software (www.empowerstats.com, X\&Y solutions, Inc Boston, Boston, Massachusetts).

\section{Results}

\section{Clinical Characteristics and Laboratory Findings of Patients}

Overall, 239 consecutive confirmed patients with COVID-19 were enrolled from January 29 to February 15, 2020. Of these 239 COVID-19 patients, 45 (18.83\%) patients developed into severe patients. The average age in the severe group was significantly higher than in non-severe group ( $54.87 \pm 13.84$ vs. $43.36 \pm 16.67$, $\mathrm{P}<0.001)$. Compared with the non-severe group, a higher percentage of the patients in the severe group had hypertension $(31.11 \%$ vs. $9.28 \%, P<0.001)$, coronary heart disease $(8.89 \%$ vs. $2.58 \%, P=0.045)$, COPD $(6.67 \%$ vs. $1.03 \%, P=0.017)$, liver disease $(8.89 \%$ vs. $2.06 \%, P=0.022)$, fever $(91.11 \%$ vs. $61.54 \%, P$ 
$<0.001)$, shortness of breath ( $37.78 \%$ vs. $6.67 \%, P<0.001)$, muscle ache $(17.78 \%$ vs. $7.69 \%, P=0.04)$ and fatigue $(60 \%$ vs. $27.69 \%, P<0.001)$ (Table 1$)$.

Table 1

Demographics and clinical features in patients with COVID-19.

\begin{tabular}{|c|c|c|c|}
\hline & $\begin{array}{l}\text { Non-severe } \\
(n=194)\end{array}$ & $\begin{array}{l}\text { Severe } \\
(n=45)\end{array}$ & P-value \\
\hline Age, years & $43.36 \pm 16.67$ & $54.87 \pm 13.84$ & $<0.001$ \\
\hline Time between onset and hospitalization, days & $6.13 \pm 4.92$ & $6.56 \pm 3.92$ & 0.588 \\
\hline Gender/Male, n (\%) & $92(47.18 \%)$ & $26(57.78 \%)$ & 0.211 \\
\hline Epidemiology & $179(92.27 \%)$ & $38(84.44 \%)$ & 0.102 \\
\hline \multicolumn{4}{|l|}{ Underlying diseases n (\%) } \\
\hline Hypertension & $18(9.28 \%)$ & $14(31.11 \%)$ & $<0.001$ \\
\hline Diabetes & 11 (5.67\%) & $4(8.89 \%)$ & 0.422 \\
\hline Coronary heart disease & $5(2.58 \%)$ & $4(8.89 \%)$ & 0.045 \\
\hline COPD & $2(1.03 \%)$ & $3(6.67 \%)$ & 0.017 \\
\hline Kidney disease & $1(0.52 \%)$ & $1(2.22 \%)$ & 0.257 \\
\hline Cerebral infarction & $5(2.58 \%)$ & $1(2.22 \%)$ & 0.891 \\
\hline Liver Disease & $4(2.06 \%)$ & $4(8.89 \%)$ & 0.022 \\
\hline \multicolumn{4}{|l|}{ Symptom n (\%) } \\
\hline Fever & $120(61.54 \%)$ & 41 (91.11\%) & $<0.001$ \\
\hline Cough & 108 (55.38\%) & 31 (68.89\%) & 0.105 \\
\hline Shortness of breath & $13(6.67 \%)$ & $17(37.78 \%)$ & $<0.001$ \\
\hline Muscle ache & $15(7.69 \%)$ & $8(17.78 \%)$ & 0.04 \\
\hline Headache & $12(6.15 \%)$ & $6(13.33 \%)$ & 0.102 \\
\hline Dizziness & $8(4.10 \%)$ & $2(4.44 \%)$ & 0.923 \\
\hline Diarrhea & $17(8.72 \%)$ & $3(6.67 \%)$ & 0.647 \\
\hline Fatigue & $54(27.69 \%)$ & $27(60.00 \%)$ & $<0.001$ \\
\hline Nausea & $7(3.59 \%)$ & $1(2.22 \%)$ & 0.641 \\
\hline Sore throat & $25(12.82 \%)$ & $2(4.44 \%)$ & 0.107 \\
\hline
\end{tabular}


Compared to the patients in non-severe group, laboratory indicators significantly increased in severe group including creatine kinase isoenzyme, creatine kinase, lactate dehydrogenase, D-dimer, neutrophils, h CRP, alanine aminotransferase, aspartate aminotransferase and urea nitrogen. Additionally, laboratory indicators that significantly decreased in the severe group included high density lipoprotein, lymphocytes, eosinophils, albumin, and albumin /globulin (Table 2). 
Table 2

Laboratory findings in patients with COVID-19.

\begin{tabular}{|c|c|c|c|c|}
\hline & $\begin{array}{l}\text { Normal } \\
\text { Range }\end{array}$ & $\begin{array}{l}\text { Non-severe } \\
(n=195)\end{array}$ & $\begin{array}{l}\text { Severe } \\
(n=45)\end{array}$ & $\begin{array}{l}\mathrm{P} \text { - } \\
\text { value }\end{array}$ \\
\hline $\begin{array}{l}\text { Creatine kinase isoenzyme, } \\
\mathrm{U} / \mathrm{L}\end{array}$ & $0-16$ & $9.85(6.15-12.47)$ & $11.40(7.60-15.8)$ & 0.045 \\
\hline Creatine kinase, $\mathrm{U} / \mathrm{L}$ & $25-170$ & $66.85(44.97-107.18)$ & $91.8(66.7-149.2)$ & $<.001$ \\
\hline Lactate dehydrogenase, $\mathrm{U} / \mathrm{L}$ & $0-252$ & $\begin{array}{l}155.80(134.05- \\
197.98)\end{array}$ & $\begin{array}{l}208.8(184.3- \\
304.4)\end{array}$ & $<0.001$ \\
\hline Triglyceride, $\mathrm{mmol} / \mathrm{L}$ & $0.56-1.77$ & $1.06(0.77-1.44)$ & $1.08(0.80-1.31)$ & 0.340 \\
\hline Total cholesterol, $\mathrm{mmol} / \mathrm{L}$ & $2.84-5.69$ & $3.78(3.24-4.34)$ & $3.67(3.08-4.14)$ & 0.056 \\
\hline $\begin{array}{l}\text { High density lipoprotein, } \\
\mathrm{mmol} / \mathrm{L}\end{array}$ & $1.14-1.91$ & $0.80(0.69-0.97)$ & $0.67(0.59-0.95)$ & 0.022 \\
\hline $\begin{array}{l}\text { Low density lipoprotein, } \\
\mathrm{mmol} / \mathrm{L}\end{array}$ & $1.0-3.0$ & $2.67(2.22-3.10)$ & $2.61(2.21-2.92)$ & 0.201 \\
\hline D-Dimer, mg/L & $0-0.5$ & $0.23(0.13-0.48)$ & $0.39(0.19-0.76)$ & $\begin{array}{l}< \\
0.001\end{array}$ \\
\hline Leucocytes, 10ه/L & $3.5-9.5$ & $4.62(3.56-5.67)$ & $4.58(3.30-5.70)$ & 0.482 \\
\hline Hemoglobin, $\mathrm{g} / \mathrm{L}$ & $110-150$ & $130(120-141)$ & $130(120-144)$ & 0.965 \\
\hline Platelet count, $10^{9} / \mathrm{L}$ & $100-300$ & 172.(140-229.5) & $162(130-202)$ & 0.177 \\
\hline Lymphocytes, \% & $20.0-50.0$ & $28.50(22.80-35.20)$ & $\begin{array}{l}19.30(14.50- \\
25.70)\end{array}$ & $<.001$ \\
\hline Neutrophils, \% & $40.0-75.0$ & $62.2(55.4-68.4)$ & $\begin{array}{l}73.20(67.00- \\
82.80)\end{array}$ & $\begin{array}{l}< \\
0.001\end{array}$ \\
\hline Eosinophils, \% & $0.4-8.0$ & $0.40(0.10-1.10)$ & $0(0-0.20)$ & $\begin{array}{l}< \\
0.001\end{array}$ \\
\hline Lymphocytes, 10区/L & $1.1-3.2$ & $1.21(0.91-1.69)$ & $0.76(0.61-1.05)$ & $\begin{array}{l}< \\
0.001\end{array}$ \\
\hline Neutrophils, 10区/L & $1.8-6.3$ & $2.84(2.13-3.54)$ & $3.36(2.21-4.24)$ & 0.025 \\
\hline Eosinophils, 10区/L & $0.02-0.52$ & $0.02(0-0.05)$ & $0(0-0.01)$ & 0.020 \\
\hline h CRP, mg/L & $0-8$ & 11.89 (3.50-24.47) & $\begin{array}{l}44.20(20.90- \\
62.50)\end{array}$ & $\begin{array}{l}< \\
0.001\end{array}$ \\
\hline $\begin{array}{l}\text { Alanine aminotransferase, } \\
\mathrm{U} / \mathrm{L}\end{array}$ & $0-40$ & $18.82(13.73-26.26)$ & $\begin{array}{l}23.87(17.12- \\
32.44)\end{array}$ & 0.004 \\
\hline
\end{tabular}

h CRP: High-sensitivity C-reactive protein 


\begin{tabular}{|lllll|}
\hline & $\begin{array}{l}\text { Normal } \\
\text { Range }\end{array}$ & $\begin{array}{l}\text { Non-severe } \\
(\mathbf{n = 1 9 5 )}\end{array}$ & $\begin{array}{l}\text { Severe } \\
(\mathbf{n = 4 5})\end{array}$ & $\begin{array}{l}\text { P- } \\
\text { value }\end{array}$ \\
\hline $\begin{array}{l}\text { Aspartate aminotransferase, } \\
\text { U/L }\end{array}$ & $0-45$ & $23.32(18.95-28.50)$ & $\begin{array}{l}30.88(26.90- \\
43.97)\end{array}$ & $<$ \\
\hline Total bilirubin, $\mu \mathrm{mol} / \mathrm{L}$ & $1.7-17.1$ & $10.77(8.21-15.39)$ & $\begin{array}{l}11.82(7.92- \\
16.82)\end{array}$ & 0.527 \\
\hline Albumin, g/L & $60-80$ & $38.91(36.22-41.69)$ & $35(30.74-37.13)$ & $<$ \\
\hline Albumin /globulin & $1.2-2.5$ & $1.52(1.35-1.77)$ & $1.31(1.15-1.53)$ & $<$ \\
\hline Creatinine, $\mu$ mol/L & $44-133$ & $50.16(39.51-63.62)$ & $\begin{array}{l}49.99(40.73- \\
61.21)\end{array}$ & 0.001 \\
\hline Urea nitrogen, mmol/L & $1.8-7.1$ & $4.15(3.16-4.96)$ & $4.46(3.45-5.67)$ & 0.017 \\
\hline h CRP: High-sensitivity C-reactive protein & & & \\
\hline
\end{tabular}

\section{Risk Factors Associated with Severe in patients with COVID-19.}

All demographic data, clinical presentation, and laboratory parameters, listed in Table 1 and Table 2, were evaluated the association with the severe risk by univariate analysis. Our analysis showed variables that displayed statistical significance with $p<0.05$ were listed in Table 3 . These variables included age, hypertension, COPD, liver disease, fever, shortness of breath, muscle ache, fatigue, creatine kinase, lactate dehydrogenase, high density lipoprotein, D-dimer, neutrophils, lymphocytes, eosinophils, hCRP, alanine aminotransferase, aspartate aminotransferase, albumin, albumin /globulin, and urea nitrogen were associated with the severe risk of patients with COVID-19 pneumonia (Table 3). We further processed the above 21 variables with multivariate logistic regression analysis and selected 8 variables that predictive of severe risk. These 8 variables were age, COPD, shortness of breath, fatigue, creatine kinase, D-dimer, lymphocytes, and h CRP (Table 3). 
Table 3

Univariate and Multivariate analysis of severe risk factors for patients with COVID19.

\begin{tabular}{|c|c|c|}
\hline \multirow[t]{2}{*}{ Characteristic } & Univariate & Multivariate \\
\hline & OR 95\% Cl & OR 95\% Cl \\
\hline Age, years & $1.05(1.02,1.07)$ * & $0.99(0.94,1.04)$ \\
\hline \multicolumn{3}{|l|}{ Hypertension } \\
\hline No & Reference & \\
\hline Yes & $4.42(1.99,9.79)$ * & \\
\hline \multicolumn{3}{|l|}{ COPD } \\
\hline No & Reference & Reference \\
\hline Yes & $6.86(1.11,42.33)$ * & $15.49(1.24,193.94)$ * \\
\hline \multicolumn{3}{|l|}{ Liver Disease } \\
\hline No & Reference & \\
\hline Yes & $4.63(1.11,19.30)$ * & \\
\hline \multicolumn{3}{|l|}{ Fever } \\
\hline No & Reference & \\
\hline Yes & $6.32(2.18,18.37)$ * & \\
\hline \multicolumn{3}{|l|}{ Shortness of breath } \\
\hline No & Reference & Reference \\
\hline Yes & $8.45(3.71,19.28)$ * & $4.01(1.13,14.27)$ * \\
\hline \multicolumn{3}{|l|}{ Muscle ache } \\
\hline No & Reference & \\
\hline Yes & $2.58(1.02,6.53)$ * & \\
\hline \multicolumn{3}{|l|}{ Fatigue } \\
\hline No & Reference & Reference \\
\hline Yes & $3.89(1.98,7.63)$ * & $3.98(1.32,12.01)$ * \\
\hline Creatine kinase, $\mathrm{U} / \mathrm{L}$ & $1.01(1.00,1.01)$ * & $1.01(1.00,1.01)$ * \\
\hline Lactate dehydrogenase, $\mathrm{U} / \mathrm{L}$ & $1.02(1.01,1.02)$ * & \\
\hline
\end{tabular}

$\mathrm{Cl}=$ confidence interval, $\mathrm{OR}=$ odd ratio. $*$ indicated $\mathrm{P}<0.05$. 


\begin{tabular}{|c|c|c|}
\hline \multirow[t]{2}{*}{ Characteristic } & Univariate & Multivariate \\
\hline & OR 95\% Cl & OR 95\% Cl \\
\hline High density lipoprotein, mmol/L & $0.17(0.03,0.91)$ * & \\
\hline D-Dimer, mg/L & $1.35(1.06,1.72)$ * & $1.20(0.89,1.62)$ \\
\hline Neutrophils, 10区/L & $1.27(1.02,1.56)$ * & \\
\hline Lymphocytes, 10区/L & $0.09(0.03,0.24)$ * & $0.27(0.06,0.87)$ * \\
\hline Eosinophils, 10区/L & $0(0,0.001)$ * & \\
\hline h CRP, mg/L & $1.05(1.03,1.07)$ * & $1.03(1.01,1.06)$ * \\
\hline Alanine aminotransferase, $\mathrm{U} / \mathrm{L}$ & $1.03(1.01,1.05)$ * & \\
\hline Aspartate aminotransferase, $\mathrm{U} / \mathrm{L}$ & $1.07(1.04,1.10)$ * & \\
\hline Albumin, g/L & $0.77(0.70,0.85)$ * & \\
\hline Albumin /globulin & $0.05(0.01,0.20)$ * & \\
\hline Urea nitrogen, mmol/L & $1.22(1.03,1.44)$ * & \\
\hline
\end{tabular}

\section{Construction and Assessment of a Novel Predictive Model}

The risk factors selected to formulate a predictive nomogram included age, COPD, shortness of breath, fatigue, creatine kinase, D-dimer, lymphocyte and hCRP (Fig. 1). The performance of the nomogram was measured by ROC curves and the area under the curve was $0.873(95 \% \mathrm{Cl}: 0.819-0.927)$, with a sensitivity of $86.7 \%$ and a specificity of $72.0 \%$ (Figure. $2 A$ ). The ROC curves showed that the model had good discrimination. In addition, calibration plots graphically showed the model had good calibration (Figure. 2B). The extent of agreement between the predicted probability and the actual probability of severe risk is shown in Figure. 2B. In addition, the Hosmer-Lemeshow test result showed that there was no significant difference $(P=0.92)$, indicating that the predicted probability closely matched the actual probability. The decision curve demonstrated that the model has additional clinical value since it had the highest net benefit across a broad range of predicted probabilities ranging from $10-70 \%$ risk (Figure. $2 \mathrm{C}$ ). This suggested that basing decisions on the model will yield an overall net benefit, as opposed to not using the model.

\section{Discussion}

The rapid and extensive spread of SARS-CoV-2 infection in China and in the world has resulted in a tremendous loss of safety in peoples' lives (15). Therefore, identifying risk factors on admission to predict the likelihood of disease progression, would be beneficial to physicians when they are making a reasonable decision on patient management. Our study provides comprehensive data on the 
epidemiological, demographic, clinical and laboratory characteristics of 239 hospitalized patients with COVID-19 in the first hospital of Changsha, which is the largest local dedicated hospital for treating COVID-19 patients. Hence, it may represent the general situation of COVID-19 infection, except for severely affected areas, such as Wuhan. In this study, the risk factors, including age, COPD, shortness of breath, fatigue, creatine kinase, D-dimer, lymphocyte and hCRP were selected to formulate a predictive nomogram to predict the severe risk of COVID-19 patients on admission. The good performance of this novel nomogram model was confirmed by the ROC curve, calibration plots and decision curve.

Previous studies have reported several clinical characteristics in severe cases and patents with adverse outcomes following COVID-19 infection. Older age, comorbidities such as hypertension, respiratory disease, diabetes, cancer, cardiovascular disease, high LDH level, and lymphocytopenia have all been associated with an increased risk of mortality $(4,9,16-18)$. Obesity and smoking have been reported to correlate with increased risks in other studies $(4,17)$. In a study from Italy, men were at higher risk than women, which could be partly due to their higher smoking rates and subsequent comorbidities (19). In our study, we also found that old age and comorbidities such as COPD were associated with severe risk in patients with COVID-19 infection. Patients who are 65 years old scored more than 30 points, and if with COPD, another 85 points will be added. Our model also included other factors, such as symptoms like shortness of breath and fatigue, laboratory data like creatine kinase, D-dimer, lymphocyte, and hCRP. If the points added exceeded 150 , the patient was noted to have the risk of progressing to the severe status, and perhaps requiring early intervention and more active treatment or even intensive care. The higher the points calculated, the higher the risk for the patient. The nomogram scoring system with 8 clinical parameters seemed to be simpler than the 12-parameter MuLBSTA score proposed in the study by Guo L et al (20).

Our study also showed that the level of D-dimer was higher in the severe group and can be used as a parameter to predict disease progression. High levels of D-dimer were correlate with 28-day mortality in patients with infection or sepsis identified in the emergency department (21). Mechanisms involved included systemic pro-inflammatory cytokine responses and local inflammation, which mediate atherosclerosis and plaque rupture, predisposing the patient to ischemia and thrombosis. This indicates that the severe patients may have high risk of embolism, thus close monitoring and early intervention are needed (22-24). Additionally, angiotensin converting enzyme 2 (ACE2), the cellular receptor for SARSCoV-2 entry, is expressed on myocytes and vascular endothelial cells $(25,26)$, hence there is, at least, a theoretical basis for direct cardiac and vascular involvement in SARS-CoV-2 infection. Our study also shows that the severe group has elevated creatine kinase, which is possibly associated with myocardial injury, as reported in several studies (27). Currently, the specific mechanism remains exclusive. Therefore, in patients with SARS-CoV-2 infection, cardiac and vascular damage cannot be ignored depending on the situation, and dynamic monitoring is recommended. As an acute phase reactive protein, CRP usually correlates positively to the severity of inflammation in many diseases. CRP has been used as a factor to predict the severity of patients with SARS and SARS-COV-2 previously and recently (23). It was confirmed again in our study that CRP level is a risk factor to predict disease severity. 
There are several limitations in our study. Firstly, the sample size was relatively small. It included only 239 patients in a single center outside Hubei province and may not be suitable for predicting the outcomes of patients in areas most severely affected by the pandemic, such as Wuhan, or regions that are experiencing large-scale outbreaks of COVID-19. Secondly, a prospective study is required to confirm the reliability of this novel nomogram model. Finally, adding other specific markers might further improve the sensitivity and specificity of the model.

\section{Conclusion}

We established a novel nomogram model of eight clinical parameters to predict disease severity of COVID-19 on admission. Application of this model with high accuracy might be beneficial for delaying or halting the progression of the disease, which may improve therapeutic treatments, reduce the severity of COVID-19, and result in more accurate and effective deployment of medical resources.

\section{Declarations}

\section{Acknowledgments}

We thank Etage for his critical reading of our manuscript.

\section{Authors' contributions}

Fang Zheng, Ning Li and Ruochan Chen designed the study. Jiyang Liu collected the data. Ruochan Chen and Run Yao analyzed the data and wrote the manuscript. All authors read and approved the final manuscript.

\section{Funding}

This study was supported by Emergency Special Science and Technology Plan Project of COVID-19 Epidemic of Changsha city (NO. kq2001006 and kq2001053), National Natural Sciences Foundation of Hunan province (NO. 2019JJ30041), and Innovation-Driven Project of Central South University (N0.2020CX044).

\section{Availability of data and materials}

Data analyzed during the current study are available from the corresponding author on reasonable request.

\section{Ethics approval and consent to participate}

This study was approved by First Hospital of Changsha city (No. 2020011). Informed consent was obtained from all patients.

\section{Consent for publication}


Not applicable.

\section{Competing interests}

The authors have declared that no conflict of interest exists.

\section{References}

1. Wang $\mathrm{H}$, Bloom $\mathrm{O}$, Zhang $\mathrm{M}$, et al. HMG-1 as a late mediator of endotoxin lethality in mice. Science. 1999;285(5425):248-51. doi:10.1126/science.285.5425.248.

2. Chen NS, Zhou M, Dong X, et al. Epidemiological and clinical characteristics of 99 cases of 2019 novel coronavirus pneumonia in Wuhan, China: a descriptive study. Lancet. 2020;395(10223):50713. DOI:10.1016/S0140-6736(20)30211-7.

3. Peng YD, Meng K, Guan HQ, et al. Clinical characteristics and outcomes of 112 cardiovascular disease patients infected by 2019-nCoV. Zhonghua Xin Xue Guan Bing Za Zhi. 2020;48(0):E004. DOI:10.3760/cma.j.cn112148-20200220-00105.

4. Wang DW, Hu B, Hu C, et al. Clinical Characteristics of 138 Hospitalized Patients With 2019 Novel Coronavirus-Infected Pneumonia in Wuhan, China. JAMA. 2020;323(11):1061-9. DOI:10.1001/jama.2020.1585.

5. Wang YX, Wang YY, Chen Y, et al. Unique epidemiological and clinical features of the emerging 2019 novel coronavirus pneumonia (COVID-19) implicate special control measures. J Med Virol. 2020. DOI:10.1002/jmv.25748.

6. Zhu Z, Cai T, Fan LY, et al. Clinical value of immune-inflammatory parameters to assess the severity of coronavirus disease 2019. Int J Infect Dis. 2020;95:332-9. DOI:10.1016/j.ijid.2020.04.041.

7. Huang CL, Wang YM, Li XW, et al. Clinical features of patients infected with 2019 novel coronavirus in Wuhan. China Lancet. 2020;395(10223):497-506. DOI:10.1016/S0140-6736(20)30183-5.

8. Zhu N, Zhang DY, Wang WL, et al. A Novel Coronavirus from Patients with Pneumonia in China, 2019. N Engl J Med. 2020;382(8):727-33. D0I:10.1056/NEJMoa2001017.

9. Wu ZY, McGoogan JM. Characteristics of and Important Lessons From the Coronavirus Disease 2019 (COVID-19) Outbreak in China: Summary of a Report of 72314 Cases From the Chinese Center for Disease Control and Prevention. JAMA. 2020;323(13):1239-42. DOI:10.1001/jama.2020.2648.

10. Al-Najjar H, Al-Rousan N. A classifier prediction model to predict the status of Coronavirus COVID-19 patients in South Korea. Eur Rev Med Pharmacol Sci. 2020;24(6):3400-3.

DOI:10.26355/eurrev_202003_20709.

11. Ji D, Zhang DW, Xu J, et al. Prediction for Progression Risk in Patients with COVID-19 Pneumonia: the CALL Score. Clin Infect Dis. 2020. DOI:10.1093/cid/ciaa414.

12. Zhou F, Yu T, Du RH, et al. Clinical course and risk factors for mortality of adult inpatients with COVID-19 in Wuhan, China: a retrospective cohort study. Lancet. 2020;395(10229):1054-62. DOI:10.1016/S0140-6736(20)30566-3. 
13. Zhou YL, Zhang ZC, Tian J, et al. Risk factors associated with disease progression in a cohort of patients infected with the 2019 novel coronavirus. Ann Palliat Med. 2020;9(2):428-36.

DOI:10.21037/apm.2020.03.26.

14. Li W, Xie B, Qiu SH, et al. Non-lab and semi-lab algorithms for screening undiagnosed diabetes: A cross-sectional study. EbioMedicine 2018. DOI:10.1016/j.ebiom.2018.08.009.

15. Ding Q, Lu PP, Fan YH, et al. The clinical characteristics of pneumonia patients coinfected with 2019 novel coronavirus and influenza virus in Wuhan, China. J Med Virol. 2020. DOI:10.1002/jmv.25781.

16. Kobayashi T, Jung S, Linton NM, et al. Communicating the Risk of Death from Novel Coronavirus Disease (COVID-19). J Clin Med. 2020;9(2):580. DOI:10.3390/jcm9020580.

17. Huang R, Zhu L, Xue LY, et al. Clinical findings of patients with coronavirus disease 2019 in Jiangsu province, China: A retrospective, multi-center study. PLoS Negl Trop Dis. 2020;14(5):e0008280. DOI:10.1371/journal.pntd.0008280.

18. $10.1111 /$ all. 14238

Zhang JJ, Dong X, Cao YY, et al. Clinical characteristics of 140 patients infected with SARS-CoV-2 in Wuhan, China. Allergy 2020. DOI:10.1111/all.14238.

19. Livingston E, Bucher K. Coronavirus Disease 2019 (COVID-19) in Italy. JAMA. 2020;323(14):1335. DOI:10.1001/jama.2020.4344.

20. Guo LX, Wei D, Zhang XX, et al. Clinical Features Predicting Mortality Risk in Patients With Viral Pneumonia: The MuLBSTA Score. Front Microbiol. 2019;10:2752. DOI:10.3389/fmicb.2019.02752.

21. Rodelo JR, De la Rosa G, Valencia ML, et al. D-dimer is a significant prognostic factor in patients with suspected infection and sepsis. Am J Emerg Med. 2012;30(9):1991-9.

DOI:10.1016/j.ajem.2012.04.033.

22. Smeeth L, Thomas SL, Hall AJ, et al. Risk of myocardial infarction and stroke after acute infection or vaccination. N Engl J Med. 2004;351(25):2611-8. DOI:10.1056/NEJMoa041747.

23. Wang JT, Sheng WH, Fang CT, et al. Clinical manifestations, laboratory findings, and treatment outcomes of SARS patients. Emerg Infect Dis. 2004;10(5):818-24. DOI:10.3201/eid1005.030640.

24. Davidson JA, Warren-Gash C. Cardiovascular complications of acute respiratory infections: current research and future directions. Expert Rev Anti Infect Ther. 2019;17(12):939-42.

DOI:10.1080/14787210.2019.1689817.

25. Gallagher PE, Ferrario CM, Tallant EA. Regulation of ACE2 in cardiac myocytes and fibroblasts. Am J Physiol Heart Circ Physiol. 2008;295(6):H2373-9. DOl:10.1152/ajpheart.00426.2008.

26. Mendoza-Torres E, Oyarzún A, Mondaca-Ruff D, et al. ACE2 and vasoactive peptides: novel players in cardiovascular/renal remodeling and hypertension. Ther Adv Cardiovasc Dis. 2015;9(4):217-37. DOI:10.1177/1753944715597623.

27. Aboughdir M, Kirwin T, Abdul Khader A, et al. Prognostic Value of Cardiovascular Biomarkers in COVID-19: A Review. Viruses. 2020;12(5):E527. DOI:10.3390/v12050527. 
Figures

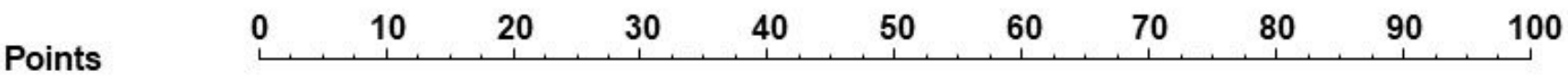
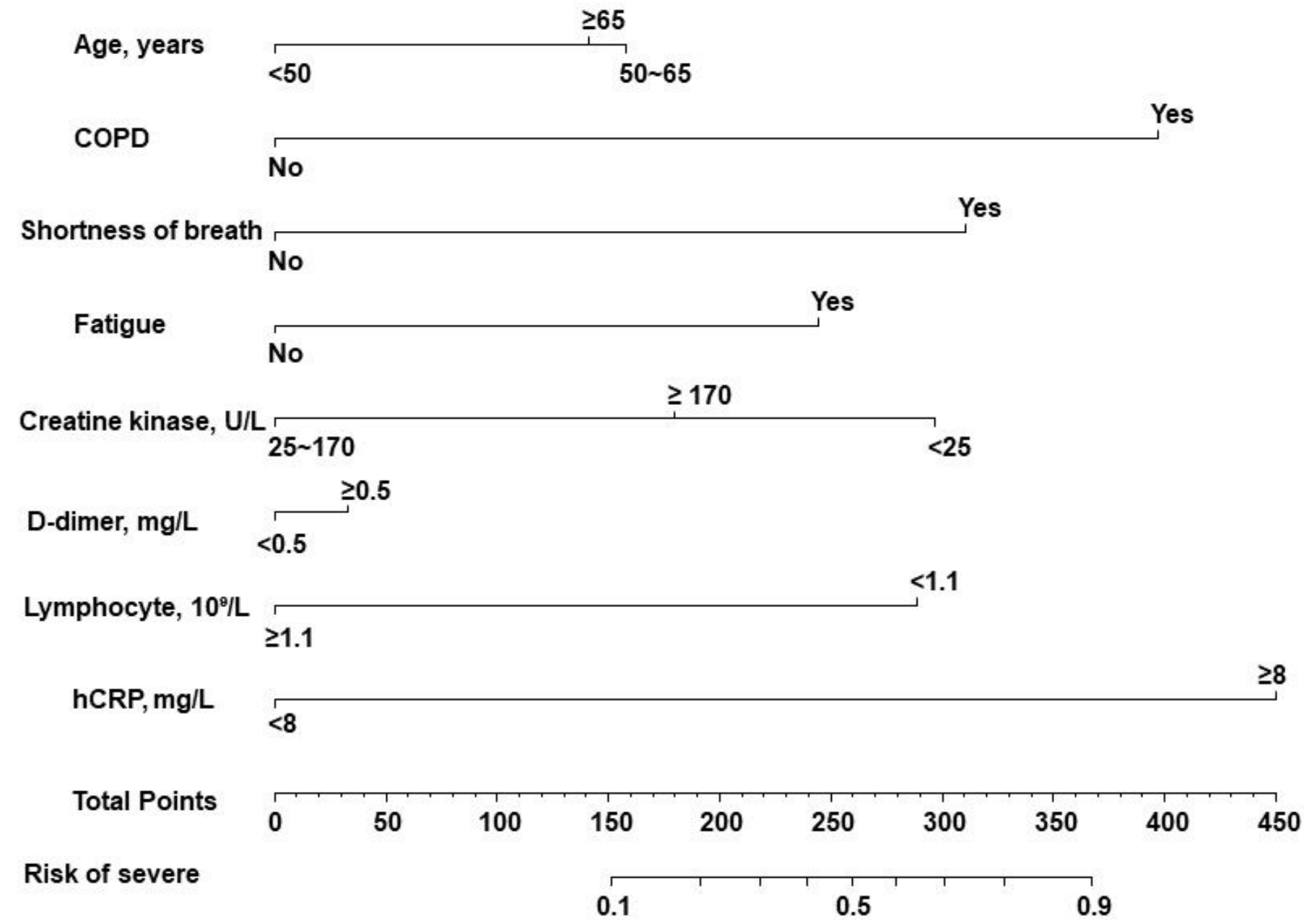

\section{Figure 1}

Nomogram to estimate the severe risk in patients with COVID-19. 

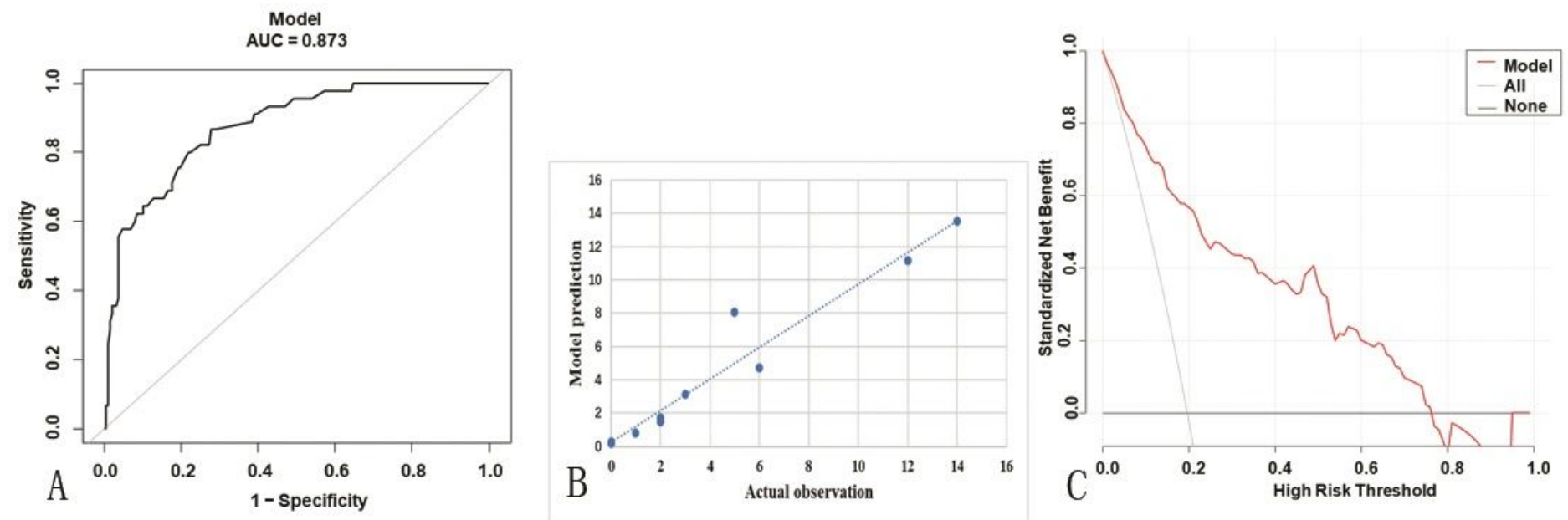

Figure 2

Construction and Assessment of a Novel Predictive Model. (A) The AUC of the model. (B) The calibration plot of the model. (C) Decision curve analysis for the model. 